\title{
Malnutrition and Metabolic Changes in Patients with Type 2 Diabetes
}

\author{
Simona Cernea ${ }^{1,2}$, Andrada Larisa Roiban ${ }^{3,4}$, Emőke Both ${ }^{3}$ \\ 1 Department M3/Internal Medicine IV, University of Medicine and Pharmacy, Tîrgu Mureş, Romania \\ 2 Diabetes, Nutrition and Metabolic Diseases Outpatient Unit, Emergency County Clinical Hospital, Tîrgu Mureş, Romania \\ 3 Emergency County Clinical Hospital, Tîrgu Mureş, Romania \\ 4 University of Medicine and Pharmacy, Tîrgu Mureș, Romania
}

\section{CORRESPONDENCE}

\section{Simona Cernea}

Str. Gheorghe Marinescu nr. 38

540139 Tîrgu Mureș, Romania

Tel: +40 265215551

E-mail: simonacernea@yahoo.com;

simona.cernea@umftgm.ro

\section{ARTICLE HISTORY}

Received: August 19, 2018

Accepted: August 31, 2018
Andrada Larisa Roiban - Str. Gheorghe Marinescu nr. 50, 540136 Tîrgu Mureș, Romania. Tel: +40 265212111 Emőke Both • Str. Gheorghe Marinescu nr. 38, 540139 Tîrgu Mureș, Romania. Tel: +40 265215551

\begin{abstract}
Background/Aim: In patients with type 2 diabetes (T2D), malnutrition has been recognized as a serious health problem mainly in hospitalized conditions, but there is little data regarding malnutrition outside hospital settings. The aim of this study was to evaluate the risk of malnutrition and associated metabolic changes in ambulatory patients with T2D. Material and methods: This analysis used data collected from 161 patients with T2D enrolled in a larger crosssectional study. Several anthropometric and metabolic parameters were obtained. Nutritional status was evaluated using the Controlling Nutritional Status (CONUT) score. Correlations between nutritional status and metabolic and anthropometric parameters of interest were examined. Results: Of all T2D patients, $29.8 \%$ had mild malnutrition (CONUT score 2-4). These patients presented lower triglyceride $(124.8 \pm 42.3 \mathrm{mg} / \mathrm{dL}$ vs. $165.7 \pm 84.3 \mathrm{mg} / \mathrm{dL}, \mathrm{p}<0.01)$ and LDL cholesterol concentrations $(62.7 \pm 20.0 \mathrm{mg} / \mathrm{dL}$ vs. $104.9 \pm 30.6 \mathrm{mg} / \mathrm{dL}, p<0.0001)$, higher leptin levels $(10.2$ [1.6-44.9] ng/mL vs. $7.3[0.9-49.8] \mathrm{ng} / \mathrm{mL}, \mathrm{p}<0.05)$ and free leptin index $(0.65$ [0.04-2.88] vs. 0.36 [0.01-3.98], $\mathrm{p}<0.05)$ compared with patients with normal nutritional status. They also had higher total body adiposity. In patients with obesity, triglycerides levels were lower in those with mild malnutrition vs. those without malnutrition (mean difference: $27.26 \mathrm{mg} /$ $d L, p<0.05$ ). Serum $C$ peptide/leptin ratio was higher in T2D patients with normal nutritional status without obesity, the differences being significant vs. the two groups with obesity (with or without malnutrition, $0.71 \pm 0.53,0.42 \pm 0.33$, and $0.49 \pm 0.68$, respectively). HOMA-IR was lower in patients with normal nutritional status without obesity vs. those with obesity (mean difference: -0.7126, $p<0.05$ ), while in patients with mild malnutrition, HOMA-IR values were higher, but no differences were noted between the groups with or without obesity. Conclusion: In patients with T2D, malnutrition associated with lower triglycerides concentrations, even in the presence of obesity. Malnutrition and/or obesity associated with higher HOMA-IR, serum leptin levels and lower $\mathrm{C}$ peptide/leptin ratio.
\end{abstract}

Keywords: type 2 diabetes, malnutrition, metabolic parameters

\section{BACKGROUND}

Malnutrition has emerged as a serious health issue, mainly in hospitalized patients, because it is associated with a poorer overall prognosis. ${ }^{1,2}$ It occurs as a result of an inadequate diet with improper quantities and/or quality of nutri- 
ents, malabsorption, or disease-related metabolic changes such as increased nutrient losses. ${ }^{3}$ Malnutrition increases the risk of acute and chronic diseases, including osteoporosis or cardio-metabolic diseases, and alters the immune and muscular functions. ${ }^{4}$ As a consequence, patients are at increased risk of infections or other complications such as impaired wound healing. ${ }^{5}$ This might be particularly relevant for patients with type 2 diabetes (T2D), since they are already at increased risk of chronic complications due to hyperglycemia. In fact, both conditions can have serious health implications.

Some reports indicate that up to a third of T2D patients admitted to the hospital are malnourished, and this is associated with a longer hospitalization and a higher mortality risk. ${ }^{3,6}$ On the other hand, diabetes has been identified as a risk factor for malnutrition in hospitalized patients. ${ }^{7}$ However, there is little data regarding malnutrition in patients with T2D outside hospital facilities.

In this study we aimed to evaluate the risk of malnutrition and associated metabolic changes in ambulatory patients with $\mathrm{T} 2 \mathrm{D}$ by using validated nutrition scores.

\section{MATERIAL AND METHODS}

\section{Study population}

This was an analysis of data obtained in a larger cross-sectional study that evaluated the role of leptin and leptin resistance in non-alcoholic fatty liver disease and in depression, in subjects with T2D. The study included adult patients with T2D, diagnosed according to the American Diabetes Association (ADA) criteria and older than 30 years of age. ${ }^{8}$ Patients attended the Diabetes Outpatient Unit of the Emergency Clinical County Hospital of Tîrgu Mureş for regular checkups and were recruited in the study during 2017. Details regarding study participants, materials, and methods have been published previously. ${ }^{9}$ The study was approved by the Ethics Committee of the University of Medicine and Pharmacy of Tîrgu Mures, and all participants signed an informed consent before being enrolled.

Apart from demographic and clinical data (which included medical history, and measurement of blood pressure $[\mathrm{BP}]$ and pulse), several anthropometric parameters were also obtained by standard methods (weight, height, waist circumference, hip circumference, and four skinfolds that evaluated subcutaneous adipose tissue [subscapular, suprailiac, biceps, triceps]).

Several laboratory data were used in the analysis. Blood samples were collected after an overnight fast, in clot activator tubes (and aliquots stored at $-80^{\circ} \mathrm{C}$ for subsequent analysis) and separately, on EDTA tubes for glycated hemoglobin (HbA1c) and complete blood count (CBC) analysis. The metabolic panel included blood glucose (measured by glucose-oxidase method), HbAlc (analyzed according to the DCCT-standardized and NGSP-certified [\%] method, based on turbidimetric inhibition immunoassay), lipid profile (total cholesterol, high-density lipoprotein [HDL] cholesterol, triglycerides), C-peptide (measured by a competitive chemiluminescent enzyme immunoassay on Immulite 2000, Diagnostic Products Corporation, USA), serum leptin and soluble form of leptin receptor (sObR, measured by sandwich enzyme-linked immunosorbent assay [ELISA] on a DSX ELISA automated analyzer, Dynex Technologies, Inc. USA). Serum albumin was also measured on Cobas Integra 400 plus (Roche Diagnostic, Germany), together with $\mathrm{HbAlc}$ and lipids. The $\mathrm{CBC}$ was analyzed on a 5-differential hematology analyzer.

\section{Calculations}

Several metabolic and anthropometric parameters were calculated. Low-density lipoprotein (LDL) cholesterol concentrations were calculated with the Friedewald formula and the Free Leptin Index (FLI), basically an estimate of leptin resistance, by using the ratio of leptin and sObR values. ${ }^{10}$ The Homeostasis Assessment Model (HOMA) calculator version 2.2.3 was used to estimate $\beta$-cell function (HOMA-B) and insulin resistance (HOMA-IR), by inputting fasting blood glucose and C-peptide values. ${ }^{11}$ The waistto-hip ratio (WHR), $\Sigma 4$ SF (the sum of 4 skinfolds), and the body mass index (BMI) were calculated. The percentage of body fat (BF) was estimated using the Durnin \& Womersley and Siri equations. ${ }^{12}$ The total body fat mass (TBFM) was calculated using the formula weight $\times \% \mathrm{BF} / 100$, and the non-fat mass (NFM) by the difference between weight and TBFM. The daily resting energy expenditure (REE) was estimated using the Harris-Benedict formula. ${ }^{13}$

The nutritional status was evaluated with the widely used and validated Controlling Nutritional Status (CONUT) score, which employs a scoring system based on serum albumin levels, total cholesterol concentrations, and total lymphocyte count. ${ }^{14} \mathrm{~A}$ total CONUT score of $0-1$ points indicates a normal nutritional status, $2-4$ points indicate mild malnutrition, 5-8 points are indicative of moderate malnutrition, while $9-12$ points indicate severe malnutrition. ${ }^{14}$ In addition, the Prognostic Nutritional Index $(\mathrm{PNI})$ was calculated using the formula: $10 \times$ serum albumin $(\mathrm{g} / \mathrm{dL})+0.005 \times$ total lymphocyte $($ count $/ \mu \mathrm{L}) .{ }^{15}$ A score of 38 or more is indicative of normal nutritional status and below 35 of severe malnutrition. ${ }^{15}$ 


\section{Statistical analysis}

Descriptive statistics was calculated for all variables. They were expressed as mean \pm SD or median (min-max) (continuous variables) or as frequency (\%) (categorical variables). Student's t-test, Mann-Whitney, ANOVA, or Kruskal-Wallis tests were used to compare means or medians between groups, and the Dunn or the Bonferroni posttests were employed to identify groups between which there were significant differences. Fisher's exact test was used for analysis of categorical variables. The correlations between variables were tested using Pearson's and Spearman's tests, respectively, and data are presented as $\mathrm{r}(95 \%$ confidence interval $[\mathrm{CI}]$ ). The tests were two-tailed, and statistical significance was set at $\mathrm{p}<0.05$. GraphPad InStat 3 was employed for analysis.

\section{RESULTS}

Data from 161 patients with T2D was analyzed and classified as having normal nutritional status (CONUT score $0-1$ points) $(70.2 \%)$ or mild malnutrition (CONUT score 2-4 points) (29.8\%). No patient presented a CONUT score $\geq 5$ points. There were no differences with regards to age ( $63.4 \pm 8.0$ years vs. $65.9 \pm 6.6$ years), gender distribution ( $66.4 \%$ vs. $72.9 \%$ females) and diabetes duration ( 6.0
[0.0-21.0] years vs. $5.5[0.0-27.0]$ years) between the two groups (p: NS for all). Their BP values (129.7 \pm 14.1/76.0 $\pm 9.7 \mathrm{mmHg}$ vs. $128.7 \pm 16.3 / 73.4 \pm 9.5 \mathrm{mmHg}$ ) and their pulse $(74.7 \pm 11.5 \mathrm{~b} / \mathrm{min}$ vs. $73.0 \pm 10.1 \mathrm{~b} / \mathrm{min})$ were similar (p: NS for all). The group with mild malnutrition according to the CONUT score also had significantly lower PNI values $(52.3 \pm 4.5$ vs. $55.0 \pm 3.6, \mathrm{p}<0.0001)$.

\section{Metabolic data}

The CONUT score correlated negatively with LDL cholesterol concentrations $(-0.78,95 \% \mathrm{CI}-0.84$ to -0.71 , $\mathrm{p}<0.0001)$, triglycerides $(-0.24,95 \% \mathrm{CI}-0.39$ to -0.08 , $\mathrm{p}<0.01$ ) (Figure 1A), HDL cholesterol $(-0.23,95 \% \mathrm{CI}$ -0.37 to $-0.07, \mathrm{p}<0.01$ ), and $\mathrm{C}$ peptide/leptin ratio $(-0.16,95 \% \mathrm{CI}-0.31$ to $0.001, \mathrm{p}<0.05)$ and positively with leptin $(0.21,95 \% \mathrm{CI} 0.05$ to $0.36, \mathrm{p}<0.01)$, FLI $(0.23$, $95 \% \mathrm{CI} 0.08$ to $0.38, \mathrm{p}<0.01)$, HOMA-B $(0.17,95 \% \mathrm{CI}$ 0.006 to $0.32, \mathrm{p}<0.05)$, and $\operatorname{REE}(0.18,95 \% \mathrm{CI} 0.02$ to $0.33, \mathrm{p}<0.05)$.

The correlations of PNI with metabolic markers were additionally studied in order to verify the results. The PNI score correlated positively with triglycerides $(0.28,95 \% \mathrm{CI}$ 0.12 to $0.42, \mathrm{p}<0.001)$ and negatively with leptin levels $(-0.19,95 \% \mathrm{CI}-0.34$ to $-0.03, \mathrm{p}<0.05)$ and FLI $(-0.17$, $95 \% \mathrm{CI}-0.32$ to $-0.01, \mathrm{p}<0.05)$.

TABLE 1. Metabolic parameters in patients with T2D with or without mild malnutrition

\begin{tabular}{|c|c|c|c|}
\hline & $\begin{array}{l}\text { CONUT score 0-1 } \\
\text { (normal nutrition status) } \\
(n=113)\end{array}$ & $\begin{array}{l}\text { CONUT score } 2-4 \\
\text { (mild malnutrition) } \\
\quad(n=48)\end{array}$ & $p$ value \\
\hline HbA1c (\%) & $6.4(5.2-12.4)$ & $6.5(5.1-9.7)$ & NS \\
\hline Fasting blood glucose (mg/dL) & $138(64-297)$ & $136(84-267)$ & NS \\
\hline Total cholesterol (mg/dL) & $175.7(140.0-326.5)$ & $128.1(91.7-200.6)$ & $<0.0001$ \\
\hline HDL cholesterol (mg/dL) & $\begin{array}{c}46.9 \pm 13.0 \\
44.5(24.0-81.7)\end{array}$ & $\begin{array}{c}43.5 \pm 9.7 \\
41.6(27.2-66.0)\end{array}$ & NS \\
\hline Triglycerides (mg/dL) & $\begin{array}{c}165.7 \pm 84.3 \\
143.6(47.7-434.9)\end{array}$ & $\begin{array}{c}124.8 \pm 42.3 \\
119.8(56.7-234.3)\end{array}$ & $<0.01$ \\
\hline LDL cholesterol (mg/dL) & $\begin{array}{c}104.9 \pm 30.6 \\
99.7(53.3-217.7)\end{array}$ & $\begin{array}{c}62.7 \pm 20.0 \\
61.0(27.5-12.1)\end{array}$ & $<0.0001$ \\
\hline C-peptide (ng/mL) & $\begin{array}{c}2.89 \pm 1.34 \\
2.67(0.33-6.52)\end{array}$ & $\begin{array}{c}3.17 \pm 1.71 \\
2.96(0.29-7.06)\end{array}$ & NS \\
\hline HOMA-B (\%) & $70.5 \pm 31.1$ & $83.3 \pm 38.5$ & $<0.05$ \\
\hline HOMA-IR & $\begin{array}{c}2.52 \pm 1.19 \\
2.38(0.45-5.92)\end{array}$ & $\begin{array}{c}2.65 \pm 1.42 \\
2.4(0.43-6.06)\end{array}$ & NS \\
\hline Leptin (ng/mL) & $7.3(0.9-49.8)$ & $10.2(1.6-44.9)$ & $<0.05$ \\
\hline $\mathrm{FLI}$ & $0.36(0.01-3.98)$ & $0.65(0.04-2.88)$ & $<0.05$ \\
\hline C-peptide/leptin ratio & $2.91(0.40-27.11)$ & $3.40(0.31-20.81)$ & NS \\
\hline REE (kcal/day) & $\begin{array}{c}1,052.3 \pm 198.1 \\
1,080.2(598.4-1,673.0)\end{array}$ & $\begin{array}{c}1,121.9 \pm 204.1 \\
1,111.2(592.6-1,821.8)\end{array}$ & $<0.05$ \\
\hline
\end{tabular}

$\mathrm{FLI}$ - free leptin index; REE - resting energy expenditure. Data are presented as mean $\pm \mathrm{SD}$ and/or median (min-max). 

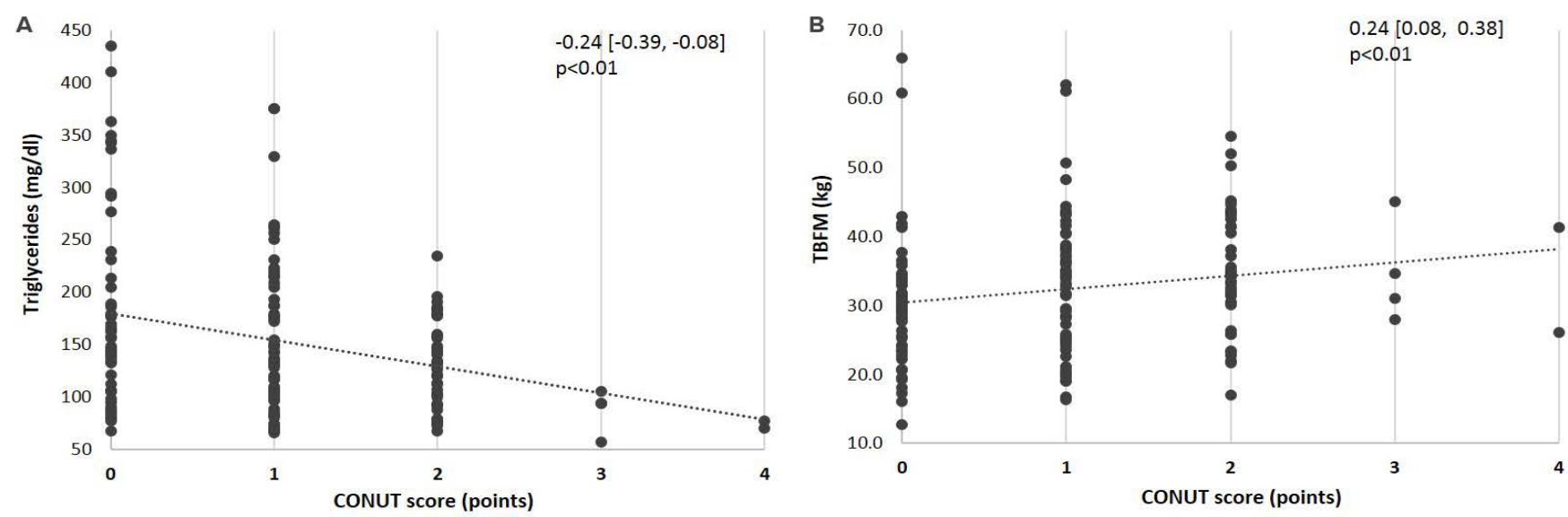

FIGURE 1. CONUT score correlations with serum triglyceride levels (A) and total body fat mass (TBFM) (B). Data is presented as $r(95 \% \mathrm{Cl})$.

There were no significant differences between the two CONUT groups with regards to fasting blood glucose, HbAlc, or HDL cholesterol levels, but triglycerides and LDL cholesterol concentrations were lower in the mild malnutrition group $(124.8 \pm 42.3 \mathrm{mg} / \mathrm{dL}$ vs. $165.7 \pm 84.3$ $\mathrm{mg} / \mathrm{dL}, \mathrm{p}<0.01$ and $62.7 \pm 20.0 \mathrm{mg} / \mathrm{dL}$ vs. $104.9 \pm 30.6$ $\mathrm{mg} / \mathrm{dL}, \mathrm{p}<0.0001$, respectively) (Table 1, Figure 2A). Additionally, although there were no significant differences between C-peptide concentrations $(2.89 \pm 1.34 \mathrm{ng} / \mathrm{mL}$ vs. $3.17 \pm 1.71 \mathrm{ng} / \mathrm{mL}, \mathrm{p}: \mathrm{NS})$, patients with mild malnutrition had higher HOMA-B values, as well as higher leptin (Figure 2B) and FLI values, indicative of higher leptin resistance (Table 1). However, when C-peptide values were divided with leptin values, the difference was no longer significant (p: NS) (Table 1). The two groups presented similar insulin resistance (HOMA-IR).

\section{Anthropometric data}

The CONUT score correlated positively with weight $(0.18$, $95 \%$ CI 0.02 to $0.33, \mathrm{p}<0.05)$, BMI $(0.23,95 \%$ CI 0.08 to $0.38, \mathrm{p}<0.01)$, waist $(0.26,95 \% \mathrm{CI} 0.11$ to $0.41, \mathrm{p}<0.001)$, hip circumference $(0.23,95 \% \mathrm{CI} 0.07$ to $0.37, \mathrm{p}<0.01)$, \%BF $(0.16,95 \% \mathrm{CI} 0.004$ to $0.31, \mathrm{p}<0.05)$, TBFM $(0.24$, $95 \%$ CI 0.08 to $0.38, \mathrm{p}<0.01)$ (Figure $1 \mathrm{~B})$, and $\Sigma 4 \mathrm{SF}(0.19$, $95 \% \mathrm{CI} 0.04$ to $0.34, \mathrm{p}<0.05)$. The PNI correlated negatively only with the hip circumference $(-0.17,95 \% \mathrm{CI}-0.32$ to $-0.01, \mathrm{p}<0.05)$.

Although the total body weight and NFM were similar between the two groups, contrary to our expectations, T2D patients with mild malnutrition had higher BMI values $\left(34.1 \pm 4.8 \mathrm{~kg} / \mathrm{m}^{2}\right.$ vs. $\left.32.2 \pm 5.0 \mathrm{~kg} / \mathrm{m}^{2}, \mathrm{p}<0.01\right)$ (Figure $2 \mathrm{C}$ ) and a higher proportion of them presented obesity

TABLE 2. Anthropometric parameters in patients with T2D with or without mild malnutrition

\begin{tabular}{|c|c|c|c|}
\hline & $\begin{array}{l}\text { CONUT score 0-1 } \\
\text { (normal nutrition status) } \\
(\mathrm{n}=113)\end{array}$ & $\begin{array}{l}\text { CONUT score } 2-4 \\
\text { (mild malnutrition) } \\
\qquad(n=48)\end{array}$ & $p$ value \\
\hline Weight (kg) & 80.5 (55.5-136.5) & $85.7(62.0-157.0)$ & NS \\
\hline BMI (kg/m²) & $\begin{array}{c}32.2 \pm 5.0 \\
31.8(21.7-49.5)\end{array}$ & $\begin{array}{c}34.2 \pm 4.8 \\
33.2(25.8-49.6)\end{array}$ & $<0.01$ \\
\hline Waist circumference (cm) & $105.5 \pm 11.1$ & $109.8 \pm 11.3$ & $<0.05$ \\
\hline Hip circumference (cm) & $\begin{array}{c}107.1 \pm 9.0 \\
106.0(91.5-142.0)\end{array}$ & $\begin{array}{c}110.4 \pm 9.0 \\
109.0(97.0-142.0)\end{array}$ & $<0.05$ \\
\hline WHR & $0.98 \pm 0.07$ & $0.99 \pm 0.06$ & NS \\
\hline$\% \mathrm{BF}$ & $41.4(14.1-51.6)$ & $42.3(22.3-47.8)$ & NS \\
\hline TBFM (kg) & $31.4 \pm 9.8$ & $34.8 \pm 8.4$ & $<0.05$ \\
\hline NFM (kg) & $47.3(34.8-83.5)$ & 49.5 (35.9-102.4) & NS \\
\hline$\Sigma 4 \mathrm{SF}(\mathrm{mm})$ & $97.1 \pm 28.4$ & $104.8 \pm 22.7$ & NS \\
\hline
\end{tabular}

BMI - body mass index; WHR - waist-to-hip ratio; \%BF - \% body fat; TBFM - total body fat mass; NFM - non-fat mass, $\Sigma 4$ SF - sum of four skinfolds. Data are presented as mean \pm SD and/or median (min-max). 

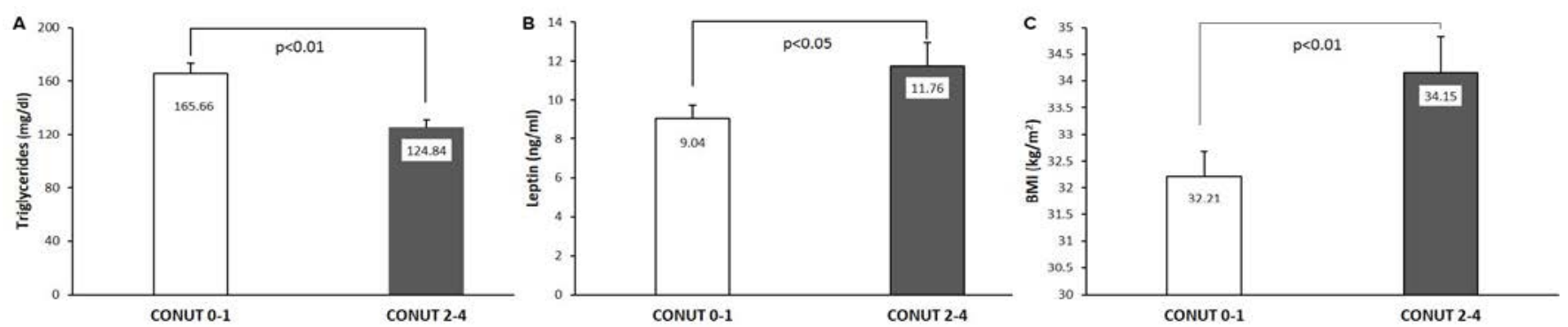

FIGURE 2. Serum triglyceride concentrations (A), serum leptin concentrations (B), and BMI (C) in patients with T2D with or without mild malnutrition. Data are presented as mean \pm SE.

( $87.5 \%$ vs. $60.2 \%, \mathrm{p}<0.001)$. T2D patients with mild malnutrition had higher body adiposity (TBFM, waist and hip circumferences, $\mathrm{p}<0.05$ for all) (Table 2 ).

\section{The impact of malnutrition and obesity on metabolic and anthropometric parameters}

In order to better discern the impact of obesity and malnutrition on metabolic changes, we have further divided the two CONUT groups according to the presence of obesity (BMI $<$ or $\geq 30 \mathrm{~kg} / \mathrm{m}^{2}$ ) and have delineated four subgroups: normal nutritional status without obesity (Group 1 ) or with obesity (Group 2), and mild malnutrition without obesity (Group 3) or with obesity (Group 4).

There was a significant difference in triglyceride values between the four groups ( $p<0.05$, Table 3 ). Patients with obesity without malnutrition had significantly higher triglyceride concentrations than those with obesity

TABLE 3. Metabolic and anthropometric variables in T2D patients with/without obesity and with/without mild malnutrition, respectively

\begin{tabular}{|c|c|c|c|c|c|}
\hline & $\begin{array}{c}\text { Group } 1 \\
\text { CONUT score 0-1 } \\
\text { BMI <30 kg/m² } \\
(\mathrm{n}=45)\end{array}$ & $\begin{array}{c}\text { Group } 2 \\
\text { CONUT score 0-1 } \\
\text { BMI } \geq 30 \mathrm{~kg} / \mathrm{m}^{2} \\
(\mathrm{n}=68)\end{array}$ & $\begin{array}{c}\text { Group } 3 \\
\text { CONUT score 2-4 } \\
\text { BMI <30 kg/m } \\
(n=6)\end{array}$ & $\begin{array}{c}\text { Group } 4 \\
\text { CONUT score 2-4 } \\
\text { BMI } \geq 30 \mathrm{~kg} / \mathrm{m}^{2} \\
(\mathrm{n}=\mathbf{4 2})\end{array}$ & $p$ value \\
\hline HbA1c (\%) & $6.3(5.2-12.4)$ & $6.5(5.3-10.3)$ & $6.0(5.4-6.5)$ & $6.5(5.1-9.7)$ & NS \\
\hline Fasting blood glucose (mg/dL) & $138.0(64.0-297.0)$ & 138.5 (99.0-289.0) & 128.5 (84.0-165.0) & $136.0(88.0-267.0)$ & NS \\
\hline Triglycerides (mg/dL) & $121.1(47.7-434.8)$ & $156.5(65.1-375.5)^{*}$ & $98.4(69.8-184.2)$ & $120.4(56.7-234.3)^{*}$ & 0.01 \\
\hline HDL cholesterol (mg/dL) & $49.6 \pm 14.4$ & $45.1 \pm 11.8$ & $40.1 \pm 7.9$ & $44.0 \pm 9.9$ & NS \\
\hline LDL cholesterol (mg/dL) & $109.4 \pm 28.5^{\$ \$}$ & $101.9 \pm 31.8^{* *}$ & $79.5 \pm 24.8$ & $60.5 \pm 18.4^{\$ \$ * *}$ & $<0.0001$ \\
\hline Leptin (ng/ml) & $\begin{array}{c}5.1 \pm 3.7 \\
3.8(0.9-18.4)^{m \pi \$ \$}\end{array}$ & $\begin{array}{c}11.6 \pm 7.9 \\
10.9(2.3-49.8)^{\Re}\end{array}$ & $\begin{array}{c}9.2 \pm 9.6 \\
7.0(1.6-27.5)\end{array}$ & $\begin{array}{c}12.1 \pm 7.9 \\
10.4(1.7-44.9)^{\$ \$}\end{array}$ & $<0.0001$ \\
\hline FLI & $\begin{array}{c}0.24 \pm 0.22 \\
0.15(0.01-1.18)^{n \times \$ \$ \$}\end{array}$ & $\begin{array}{c}0.72 \pm 0.6 \\
0.58(0.06-2.98)^{n+1 / 1}\end{array}$ & $\begin{array}{c}0.25 \pm 0.25 \\
0.17(0.04-0.69)^{\wedge \#}\end{array}$ & $\begin{array}{c}0.78 \pm 0.6 \\
0.71(0.09-2.88)^{\$ \$ \#}\end{array}$ & $<0.0001$ \\
\hline C peptide (ng/ml) & $2.39 \pm 1.111^{\Uparrow}$ & $3.22 \pm 1.39 \pi$ & $3.01 \pm 1.80$ & $3.19 \pm 1.73$ & $<0.05$ \\
\hline HOMA-B (\%) & $60.6 \pm 26.0 \$ \$$ & $77.0 \pm 32.5$ & $84.3 \pm 21.6$ & $83.2 \pm 40.5 \$ \$$ & $<0.01$ \\
\hline HOMA-IR & $2.08 \pm 0.99 \Re$ & $2.80 \pm 1.23^{\prime \prime}$ & $2.55 \pm 1.52$ & $2.67 \pm 1.43$ & $<0.05$ \\
\hline C peptide/leptin ratio & $\begin{array}{c}0.71 \pm 0.53 \\
0.60(0.06-2.49)^{1 \$}\end{array}$ & $\begin{array}{c}0.42 \pm 0.33 \\
0.28(0.04-1.4)^{n}\end{array}$ & $\begin{array}{c}0.53 \pm 0.41 \\
0.47(0.09-1.21)\end{array}$ & $\begin{array}{c}0.49 \pm 0.68 \\
0.29(0.05-3.19)^{\$}\end{array}$ & $<0.01$ \\
\hline REE (kcal/day) & $913.5 \pm 161.311 \$$ & $1,144.2 \pm 164.4 \pi \pi^{n}$ & $895.9 \pm 162.8^{\wedge \wedge \#}$ & $1,154.2 \pm 189.7 \$ \$ \#$ & $<0.0001$ \\
\hline Waist circumference (cm) & $97.3 \pm 7.011 \$ \$$ & $110.9 \pm 10.0 \pi$ & $97.8 \pm 7.6^{\wedge \#}$ & $111.6 \pm 10.8^{\$ \$ \#}$ & $<0.0001$ \\
\hline Hip circumference $(\mathrm{cm})$ & $100.5 \pm 5.119 \$ \$$ & $111.5 \pm 8.3^{19 \wedge}$ & $100.0 \pm 3.2^{\wedge \#}$ & $111.9 \pm 8.6^{\$ \$ \#}$ & $<0.0001$ \\
\hline TBFM $(k g)$ & $24.6 \pm 6.2^{919 \$}$ & $35.9 \pm 9.2^{4 \pi \wedge}$ & $25.1 \pm 5.0^{\wedge \#}$ & $36.2 \pm 7.9 \$ \$ \#$ & $<0.0001$ \\
\hline NFM (kg) & $44.6(34.8-68.2)^{n}$ & $47.8(40.2-83.5)^{\pi}$ & $42.5(35.9-66.6)$ & 49.8 (39.5-102.4) & $<0.01$ \\
\hline$\% \mathrm{BF}$ & $37.9(14.1-45.5)^{11 \$ \$}$ & $43.1(21.7-51.6)^{\Re}$ & $40.8(22.3-42.2)$ & $42.6(24.0-47.8)^{\$ \$}$ & $<0.0001$ \\
\hline$\Sigma 4 \mathrm{SF}(\mathrm{mm})$ & $78.8 \pm 20.619 \$$ & $109.2 \pm 26.4 \pi 9 \wedge$ & $82.8 \pm 15.9^{\wedge}$ & $107.9 \pm 21.8 \$ \$$ & $<0.0001$ \\
\hline
\end{tabular}

$\mathrm{FLI}$ - free leptin index; REE - resting energy expenditure; \%BF - \% body fat; TBFM - total body fat mass; NFM - non-fat mass; $\Sigma 4 \mathrm{SF}$ - sum of four skinfolds. Data are presented as mean \pm SD and/ or median (min-max).

* Group 2 vs. Group 4: $p<0.05$; ** Group 2 vs. Group 4: $p<0.001$; \$ Group 1 vs. Group 4: $p<0.001$; пा Group 1 vs. Group 2: $p<0.001 ; \wedge$ Group 2 vs. Group 3: $p<0.05$; \# Group 3 vs. Group 4: $p<0.05$; " Group 1 vs. Group 2: $p<0.05$; \$ Group 1 vs. Group 4: $p<0.01$; \#\# Group 3 vs. Group 4: $p<0.01$; ^^ Group 2 vs. Group 3: $p<0.01$ 

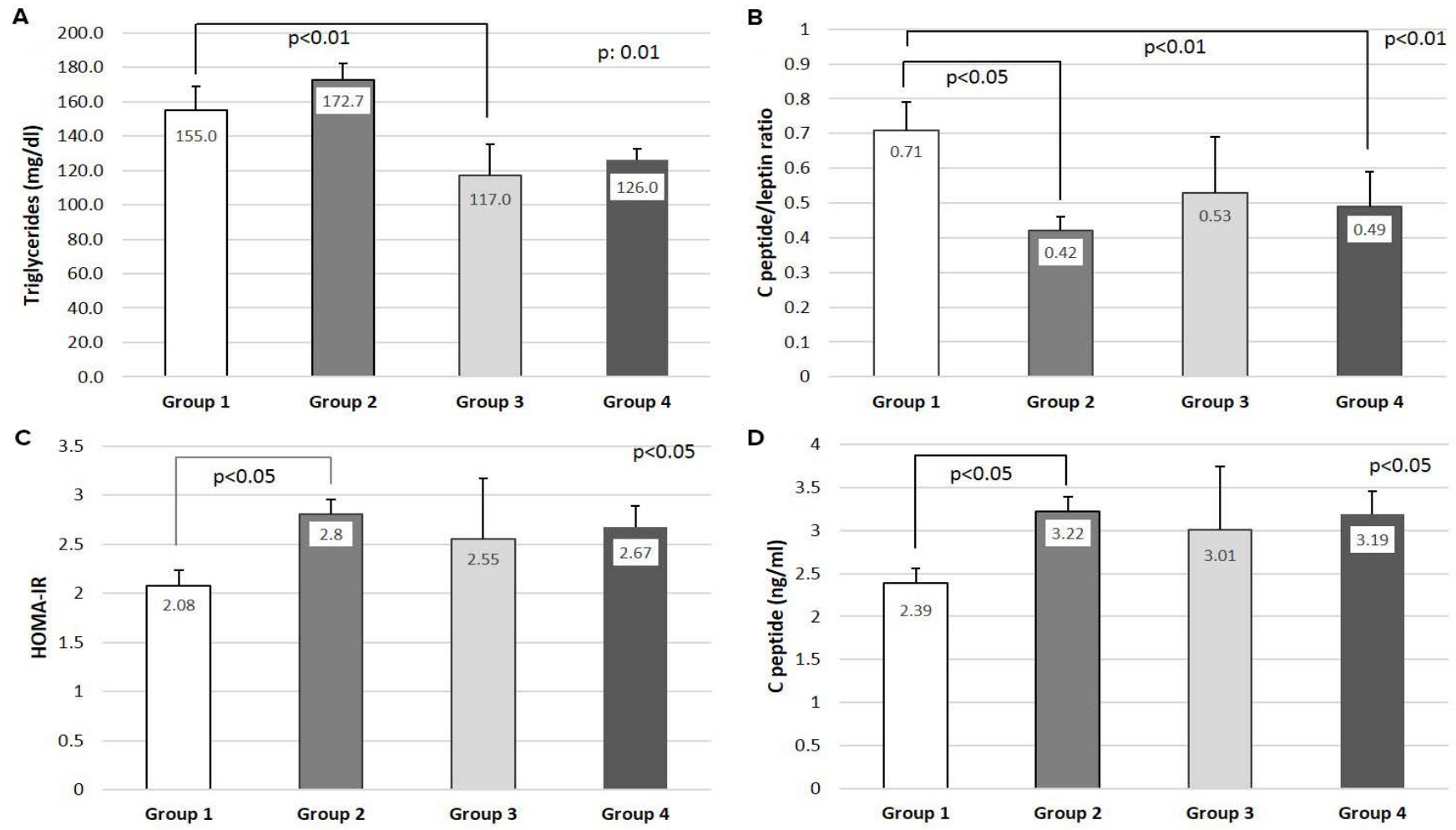

FIGURE 3. Differences in triglyceride concentrations (A), C-peptide/leptin ratio (B), HOMA-IR (C), and C-peptide (D) values in the four groups of patients with T2D: Group 1 - without malnutrition and without obesity; Group 2 - without malnutrition and with obesity; Group 3 - with mild malnutrition and without obesity; Group 4 - with mild malnutrition and with obesity. Data are presented as mean \pm SE.

and mild malnutrition (mean difference: $27.26 \mathrm{mg} / \mathrm{dL}$, $\mathrm{p}<0.05$ ) (Figure 3A). There were also significant differences between the four groups with regards to FLI and several anthropometric parameters (Table 3), but this mostly reflected the presence of obesity. Serum leptin levels and HOMA-B were lower in T2D patients with normal nutritional status without obesity, while the C-peptide/ leptin ratio was higher, the differences being significant vs. groups 2 and 4 (with obesity) (Table 3, Figure 3B). Serum C-peptide concentrations and HOMA-IR were lower in T2D patients with normal nutritional status without obesity vs. those with obesity (mean difference: $-26.749 \mathrm{ng} /$ $\mathrm{mL}$ and -0.7126 , respectively, $\mathrm{p}<0.05$ for both), indicating higher insulin resistance in this group (Group 2), while in patients with mild malnutrition, the respective values were higher, but no differences were noted between the groups with or without obesity (Group 3 vs. Group 4) (Table 3, Figure 3C and 3D).

\section{DISCUSSION}

This study evaluated the nutritional status of adult ambulatory patients with $\mathrm{T} 2 \mathrm{D}$ by using the CONUT score, an index that reflects the immune function and nutritional status of the body and that has been mainly used in cardiovascular, hepatic, and oncologic diseases so far.

The first finding of this study was that about a third of outpatients with T2D have mild malnutrition. Other studies also indicated an increased prevalence of malnutrition and malnutrition risk in patients with $\mathrm{T} 2 \mathrm{D}$, mainly elderly inpatients. $3,16,17$ The causes may be multiple. Advanced age or the presence of chronic complications, mainly diabetic nephropathy, have been shown to be associated with malnutrition. ${ }^{17,18}$ T2D patients with diabetic nephropathy/ chronic kidney disease (CKD) may follow a diet with decreased protein intake as part of their disease management and on the other hand, CKD associates with elevated protein catabolism and protein malnutrition. ${ }^{19,20}$

Another observation in this analysis was that malnutrition was present even in patients with obesity. Usually, malnutrition is associated with underweight/weight loss, but certain features of malnutrition can occur even in subjects with higher BMI. One of the studies mentioned above indicated that $15 \%$ of malnourished T2D patients were obese. ${ }^{17}$ Although at first sight this might be surprising, in fact, obesity and malnutrition are not reciprocally exclu- 
sive. A study in a large population of critically ill adults has demonstrated that obese patients with malnutrition had poorer outcomes than obese patients without malnutrition. ${ }^{21}$ In fact, it has been recognized that poor diets may provide sufficient energy to meet or even exceed the needs, but may lack the quality required for an optimal health status, and may associate with subclinical nutrient deficiencies. ${ }^{22}$ Actually, excessive body fat may hide sarcopenia and/or altered immune function and induce false clinical judgment. Moreover, obesity and diabetes may be associated with micronutrient deficiencies, such as thiamine, vitamin $\mathrm{D}$, zinc, chromium etc., that play a role in glucose metabolism, insulin secretion, and signaling pathways. ${ }^{23}$ Therefore, T2D patients with obesity should be evaluated for malnutrition as well.

We found that T2D patients with malnutrition had significantly lower triglycerides, even in the presence of obesity. Another study in elderly hypertensive subjects that used the CONUT scoring system to evaluate the nutritional status reported similar results: triglyceride concentrations decreased with malnutrition severity. ${ }^{24}$ In both studies, patients with malnutrition also had lower LDL cholesterol levels. ${ }^{24}$ It could be argued however, that since the CONUT score uses total cholesterol values as a parameter for scoring, the findings could be biased. In a different study that evaluated the nutritional status of patients with acute myocardial infarction by using the PNI, the authors similarly reported that patients with malnutrition had lower levels of serum triglycerides. ${ }^{25}$ The causes are not entirely clear, but it is possible that in malnutrition there is an impairment in the body's ability to mobilize substrates, including triglycerides, and/or substrate malabsorption.

In addition, we found that patients with mild malnutrition had higher HOMA-B, serum leptin concentrations and leptin resistance, but this could be related to higher body adiposity observed in this group. In order to decipher the role of obesity, the data was further analyzed according to both malnutrition and obesity status. In T2D patients with normal nutritional status, obesity was associated with higher insulin resistance, serum C-peptide, and leptin levels, and lower C-peptide/leptin ratio. Patients with mild malnutrition had higher values of HOMA-IR, serum C-peptide, and leptin concentrations, and lower C peptide/leptin ratio, but there were no significant differences between those with and without obesity, suggesting that malnutrition per se may be associated with these changes. Animal data showed that chronic malnutrition is associated with insulin resistance, both through receptor and post-receptor defects. ${ }^{26,27}$ There is limited data in humans in this regard.
The study had several limitations. First, it was a single center evaluation, with relatively low number of patients with mild malnutrition (mainly the subgroup without obesity). Moreover, no patient presented more severe degrees of malnutrition, which would have been helpful to better understand the metabolic changes associated with this condition. Second, it was a cross-sectional study, and the collection of prospective data would certainly add value. Third, perhaps different methods of nutritional assessment should be further employed in order to validate the results.

\section{CONCLUSIONS}

According to our results, in T2D patients, malnutrition is associated with lower triglyceride levels, even in the presence of obesity, and malnutrition and/or obesity is associated with higher HOMA-IR and serum leptin levels, and lower $\mathrm{C}$ peptide/leptin ratio.

\section{CONFLICT OF INTEREST}

Nothing to declare.

\section{ACKNOWLEDGEMENTS}

This work was supported by the University of Medicine and Pharmacy of Tîrgu Mureş Internal Research Grant (number 275/2/11.01.2017).

The laboratory analyses were done with the technical support of the Center for Advanced Medical and Pharmaceutical Research, University of Medicine and Pharmacy of Tîrgu Mureș, Romania.

The authors thank Liliana Demian, Adina Huţanu, Ştefan Barbu, Mirela Pasztor, and Maria Mureşan for their valuable technical assistance.

\section{REFERENCES}

1. Cernea S. Nutritional Status and Clinical Outcomes of Cardiac Patients in Acute Settings. Journal of Cardiovascular Emergencies. 2018;4:5-7.

2. White JV, Guenter P, Jensen G, et al. Consensus statement: Academy of Nutrition and Dietetics and American Society for Parenteral and Enteral Nutrition: Characteristics recommended for the identification and documentation of adult malnutrition (undernutrition). JPEN J Parenter Enteral Nutr. 2012;36:275-283.

3. León-Sanz M, Álvarez Hernández J, Planas M, et al. Prevalence of Hospital Malnutrition in Patients with Diabetes Mellitus: A Sub-Analysis of the PREDyCES ${ }^{\circledR}$ Study. SM J Public Health Epidemiol. 2015;1:1018.

4. Norman K, Pichard C, Lochs H, Pirlich M. Prognostic impact of disease related malnutrition. Clin Nutr. 2008;27:5-15.

5. Haydock DA, Hill GL. Impaired wound healing in surgical patients with varying degrees of malnutrition. JPEN J Parenter Enteral Nutr. 1986;10:550-554.

6. Liu GX, Chen Y, Yang $Y X$, et al. Pilot study of the Mini Nutritional Assessment on predicting outcomes in older adults with type 2 diabetes. Geriatr Gerontol Int. 2017;17:2485-2492. 
7. Álvarez-Hernández J, Planas Vila M, León-Sanz M, et al. PREDyCES researchers. Prevalence and costs of malnutrition in hospitalized patients; the PREDyCES Study. Nutr Hosp. 2012;27:1049-1059.

8. American Diabetes Association. Standards of Medical Care in Diabetes. Diabetes Care. 2015;38:S41-S48.

9. Cernea S, Roiban AL, Both E, Huțanu A. Serum leptin and leptin resistance correlations with NAFLD in patients with type 2 diabetes. Diabetes Metab Res Rev. 2018:e3050

10. Herrick JE, Panza GS, Gollie JM. Leptin, Leptin Soluble Receptor, and the Free Leptin Index following a Diet and Physical Activity Lifestyle Intervention in Obese Males and Females. J Obes. 2016;2016:8375828.

11. HOMA software. Available at: https://www.dtu.ox.ac.uk/homacalculator/ download.php.

12. Durnin J, Womersley J. Body fat assessed from total body density and its estimation from skinfold thickness: measurements on 481 men and women aged from 16 to 72 years. Br J Nutr. 1974;32:77-97.

13. Harris JA, Benedict FG. A Biometric study of human basal metabolism. Proc Natl Acad Sci U S A. 1918;4:370-373.

14. Ignacio de Ulíbarri J, González-Madroño A, de Villar NG, et al. CONUT: a tool for controlling nutritional status. First validation in a hospital population. Nutr Hosp. 2005;20:38-45.

15. Narumi T, Arimoto T, Funayama A, et al. Prognostic importance of objective nutritional indexes in patients with chronic heart failure. J Cardiol. 2013;62:307-313

16. Vischer UM, Perrenoud L, Genet C, et al. The high prevalence of malnutrition in elderly diabetic patients: implications for anti-diabetic drug treatments. Diabet Med. 2010;27:918-924.

17. Sanz París A, García JM, Gómez-Candela C, et al. Study VIDA group. Malnutrition prevalence in hospitalized elderly diabetic patients. Nutr Hosp. 2013;28:592-599.
18. Khan MS, Chandanpreet S, Kewal K, et al. Malnutrition, anthropometric and biochemical abnormalities in patients with diabetic nephropathy. $J$ Ren Nutr. 2009;19:275-282.

19. Willingham F. The dietary management of patients with diabetes and renal disease: challenges and practicalities. J Ren Care. 2012;38(Suppl1):40-51.

20. Zha $Y$, Qian Q. Protein Nutrition and Malnutrition in CKD and ESRD Nutrients. 2017;9: E208.

21. Robinson MK, Mogensen KM, Casey JD, et al. The relationship among obesity, nutritional status, and mortality in the critically ill. Crit Care Med. 2015;43:87-100

22. Tanumihardjo SA, Anderson C, Kaufer-Horwitz M, et al. Poverty, obesity, and malnutrition: an international perspective recognizing the paradox. $J$ Am Diet Assoc. 2007:107:1966-1972.

23. Via M. The malnutrition of obesity: micronutrient deficiencies that promote diabetes. ISRN Endocrinol. 2012;2012:103472.

24. Sun X, Luo L, Zhao X, Ye P. Controlling Nutritional Status (CONUT) score as a predictor of all-cause mortality in elderly hypertensive patients: a prospective follow-up study. BMJ Open. 2017;7:e015649.

25. Chen QJ, Qu HJ, Li DZ, et al. Prognostic nutritional index predicts clinical outcome in patients with acute ST-segment elevation myocardial infarction undergoing primary percutaneous coronary intervention. Sci Rep. 2017;7:3285

26. Dalvi PS, Yang S, Swain N, et al. Long-term metabolic effects of malnutrition: Liver steatosis and insulin resistance following early-life protein restriction. PLoS One. 2018;13:e0199916.

27. Rao RH, Menon RK. Chronic malnutrition impairs insulin sensitivity through both receptor and postreceptor defects in rats with mild streptozocin diabetes. Metabolism. 1993;42:772-779. 